\title{
Aprender e ensinar em contexto de incerteza nos cursos de Turismo e Hotelaria da Universidade Federal do Maranhão
}

\author{
Learning and teaching in a context of uncertainty in tourism and hospitality courses at the Federal \\ University of Maranhão \\ Aprender y enseñar en un contexto de incertidumbre en los cursos de turismo y hostelería de la Uni- \\ versidad Federal de Maranhão
}

\author{
Jonilson Costa Correia \\ Universidade Federal do Maranhão, Departamento de Turismo e Hotelaria, \\ São Luís, Maranhão, Brasil \\ angrajonilson@yahoo.com.br| https://orcid.org/0000-0003-4719-6517
}

\begin{abstract}
Resumo
Este estudo tem como objetivo apresentar as atividades ofertadas pelos professores dos cursos de Turismo e Hotelaria da Universidade Federal do Maranhão no período de pandemia da COVID-19 e, além disso, tem como objetivo específico verificar como os alunos percebem o ensino e a aprendizagem remotos neste contexto. $O$ estudo tem abordagem qualitativa e se desenvolve a partir de um duplo caminho: a revisão bibliográfica e o estudo de caso. Foi aplicado um questionário semiestruturado para os alunos dos cursos de Turismo e Hotelaria no formato Google forms. Em suas narrativas os alunos demonstram que há pontos positivos e negativos nesse momento, mas que tanto as instituições como professores e alunos estão se reinventando e explorando novos caminhos para aprender e ensinar com o uso de tecnologias digitais. Também que é necessária a implantação de políticas públicas para inclusão de todos os envolvidos neste processo de ensino e aprendizagem remoto.

Palavras-chave: Aprender. Ensinar. Pandemia. Turismo. Hotelaria.
\end{abstract}

\section{Abstract}

This study aims to present the activities offered by professors of the Tourism and Hospitality courses at the Federal University of Maranhão during the pandemic period of COVID-19, and, in addition, has the specific objective of verifying how students perceive teaching and learning remote in this context. The study has a qualitative approach, and develops from a double path: the bibliographic review and the case study. A semi-structured questionnaire was applied to students of tourism and hospitality courses in the Google forms format. In their narratives, students demonstrate that there are positive and negative points at this moment, but that both the Institutions, as teachers and students are reinventing themselves, and exploring new ways to learn and teach with the use of digital technologies. It is also necessary to implement public policies to include everyone involved in this process of teaching and remote learning.

Keywords: Learning. To teach. Pandemic. Tourism. Hospitality.

\section{Resumen}

Este estudio tiene como objetivo presentar las actividades ofrecidas por los profesores de los cursos de Turismo y Hostelería de la Universidad Federal de Maranhão durante el período pandémico de COVID-19, y, además, tiene el objetivo específico de verificar cómo los estudiantes perciben la enseñanza y el aprendizaje a distancia en este contexto. El estudio tiene un enfoque cualitativo, y se desarrolla a partir de una doble vía: la revisión bibliográfica y el estudio de caso. Se aplicó un cuestionario semiestructurado a estudiantes de cursos de turismo y hostelería en el formato de formularios de Google. En sus narrativas, los alumnos demuestran que existen puntos positivos y negativos en este momento, pero que tanto las Instituciones, como profesores y alumnos se están reinventando y explorando nuevas formas de aprender y enseñar con el uso de las tecnologías digitales. También es necesario implementar políticas públicas para incluir a todos los involucrados en este proceso de enseñanza y aprendizaje a distancia.

Palabras clave: Aprendizaje. Enseñar. Pandemia. Turismo. Hospitalidad.

Artigo recebido em: 14/10/2020 | Aprovado em: 05/01/2021 | Publicado em: 01/08/2021

\section{Como citar:}

CORREIA, Jonilson Costa. Aprender e ensinar em contexto de incerteza nos cursos de Turismo e Hotelaria da Universidade Federal do Maranhão. Pesquisa e Debate em Educação, Juiz de Fora: UFJF, v. 11, n. 2, p. 01-15, e32556, jul./dez. 2021. ISSN 2237-9444. DOI: https://doi.org/10.34019/2237-9444.2021.v11.32556. 


\section{Introdução}

Em março de 2020, a Organização Mundial da Saúde (OMS) declarou oficialmente o novo coronavírus (COVID-19) como uma pandemia. Uma das recomendações dadas pelo órgão de saúde mundial foi o distanciamento social e, com isso, a suspensão das aulas presenciais nas escolas de Educação Básica e instituições de Ensino Superior, públicas e privadas. Logo após essa declaração o MEC (Ministério da Educação) publicou a Portaria no 343, que "dispõe sobre a substituição das aulas presenciais por aulas em meios digitais enquanto durar a situação de pandemia do Novo Coronavírus (COVID19)".

Nesse cenário o ano de 2020 é considerado como um ano de crise, mas é também um ano de mudanças. E como dizem Morin e Díaz (2016, p. 5), "um mundo em crise é um mundo em transformação, em risco e oportunidade de mudança". As bases dos aparelhos do estado (religioso, escolar, familiar, jurídico, político, da informação, dentre outros) estão passando por adaptações e por metamorfoses causadas pelo crescimento quantitativo da pandemia do novo coronavírus.

Nesse contexto o aparelho escolar, que compreende o sistema das diferentes escolas públicas e particulares, realiza o ensino remoto como forma de minimizar a distância entre estudantes e professores durante a pandemia, experimentar outras possibilidades de produção do conhecimento, fomentar trocas entre professores e alunos, assim como dar conta do calendário das aulas. Podemos nos questionar, por que os professores e estudantes se tornaram o centro dessa situação?

Segundo Arruda (2020), a escola é um dos espaços sociais em que há maiores trocas e mobilidades de sujeitos de diferentes faixas etárias, portanto, representa espaço de maior probabilidade de contaminação em massa - o que indica ser um dos últimos espaços a ser reaberto em países que controlaram minimamente a taxa de contaminação do novo coronavírus.

Neste momento de pandemia e considerando que as tecnologias estão se incorporando mais intensamente nas práticas de ensino, a melhor solução para os alunos e professores consistirá em processos de ensinar e aprender mediados por recursos e possibilidades no formato online. É nesse sentido que muitas Instituições Federais de Ensino Superior (IFES) retomaram as atividades acadêmicas.

Cabe informar que, de acordo com dados do Ministério da Educação, de 21 de maio de 2020, das 69 universidades federais brasileiras, 56 estavam com as atividades acadêmicas de graduação totalmente suspensas e 13 estavam com atividades na graduação funcionando parcialmente ou totalmente. Na Universidade Federal do Maranhão - UFMA, com a publicação da Resolução no 1.999/2020-Consepe, estabeleceu-se o Calendário Acadêmico Especial da Graduação. Esta foi a primeira iniciativa desde a paralisação em março de 2020. Esse documento trata da oferta de componentes curriculares ministrados de forma remota, por conta do isolamento social. Antes da publicação dessa Resolução, realizou-se uma consulta à comunidade acadêmica (docentes, discentes e técnicos administrativos), com a finalidade de gerar um relatório sobre o uso de metodologias em educação remota. 
O relatório da consulta comprova que $67 \%$ dos professores apresentaram o apoio ao retorno das atividades acadêmicas de forma remota. Já no caso dos estudantes, um total de $70,2 \%$ da comunidade estudantil apoia o retorno das atividades acadêmicas de forma remota.

A partir dessa discussão mais ampla e obedecendo às especificidades de cada curso da universidade, os cursos de Hotelaria e Turismo - UFMA ofertaram nos meses de junho e julho de 2020 uma série de atividades (webinários, webcursos e lives), sobre temas relacionados às áreas que são atendidas pelos docentes dos cursos, tais como: gastronomia, hospitalidade, hotelaria, eventos, patrimônio, marketing e metodologias de pesquisa.

O estudo dialoga com o campo da educação na tentativa de contribuir para o entendimento teórico-metodológico sobre aulas em meios digitais no processo de ensino e aprendizagem na educação superior. Também faz parte do referencial teórico deste trabalho os documentos/normativas que discutem no âmbito do Ministério da Educação e Instituições de Ensino Superior - IFES as questões de atividades remotas nos cursos de graduação.

Inicialmente abordamos o diálogo teórico sobre ensino remoto e educação a distância destacando suas diferenças e semelhanças. Em seguida, apresentamos os procedimentos metodológicos e a descrição dos resultados alcançados com a pesquisa. Posteriormente, discutem-se as considerações finais acerca do tema.

Este estudo tem como objetivo apresentar o quadro de atividades realizadas pelos professores dos cursos de Hotelaria e Turismo da Universidade Federal do Maranhão e, além disso, de modo mais específico, verificar como os alunos percebem o ensino e a aprendizagem neste contexto de pandemia.

\section{Notas sobre educação a distância e ensino remoto}

O Ensino Remoto Emergencial (ERE) não pode ser confundido com a Educação a Distância (EaD). O modelo do ERE é adotado em situações emergenciais para apoiar a aprendizagem dos educandos, mas não se configura como uma modalidade educacional com regulamentação própria, como ocorre na EaD.

A EaD é uma modalidade educacional que prioriza a mediação didático-pedagógica por meio de tecnologias digitais de informação e comunicação (TDIC), com corpo profissional qualificado, políticas de acesso, acompanhamento e avaliação compatíveis na realização de atividades educativas por estudantes e profissionais da educação que estejam em lugares e tempos diversos (BRASIL, Decreto MEC no 9.057, de 25 de maio de 2017).

Arruda (2020) apresenta um debate interessante sobre a educação em tempos de pandemia. No seu texto, um dos primeiros pontos abordados são as distinções entre educação remota e educação a distância. Para esse autor, apesar de os termos serem amplamente difundidos como sinônimos, Educação a Distância (EAD) torna-se mais abrangente, porque implica não somente o uso de sistemas online, mas também analógicos como materiais impressos. Só para entender melhor esse ponto de vista, no Decreto no 9057/2017 está dito o seguinte: 
Para fins deste Decreto, considera-se educação a distância a modalidade educacional na qual a mediação didático-pedagógica nos processos de ensino e aprendizagem ocorra com a utilização de meios e tecnologias de informação e comunicação, com pessoal qualificado, com políticas de acesso, com acompanhamento e avaliação compatíveis entre outros, e desenvolva atividades educativas por estudantes e profissionais da educação que estejam em lugares e tempos diversos (BRASIL, 2017).

Além disso, Maia e Mattar (2008) explicam que a EaD deve considerar aspectos como planejamento anterior, o perfil de aluno e docente, desenvolvimento a médio e longo prazo de estratégias de ensino e aprendizagem que levem em consideração as dimensões síncronas e assíncronas da $\mathrm{EaD}$, assim como a participação de diferentes profissionais para o desenvolvimento de produtos que tenham, além da qualidade pedagógica, qualidade estética que é elaborada por profissionais que apoiam o professor na edição de materiais.

Desse modo, Hodges et al. (2020) vêm esclarecendo que a educação remota por meio digital é diferente da Educação a Distância pelo caráter emergencial que propõe usos e apropriações das tecnologias em circunstâncias específicas de atendimento onde antes existia regularmente o ensino presencial.

A partir do exposto observa-se que, a EaD é a base didático-metodológica do ensino remoto, é possível identificar características que confirmam esta afirmação: atividades e aulas síncronas e assíncronas; interações entre professores e alunos através de ferramentas digitais; o professor sana as dúvidas com uso de chats, fóruns e outros mecanismos que podem auxiliar no aprendizado remoto.

Saraiva e Veiga Neto (2009) explicam que, no ensino remoto, é necessário, em geral, um envio de evidências de desenvolvimento de atividades não avaliativas, que funcionam como uma forma de controle do uso do tempo, uma das características da disciplina e, na EaD, as atividades a serem desenvolvidas são, na maior parte das vezes, avaliações. Os processos de EaD não têm como foco, portanto, o controle do uso do tempo, mas apenas a demonstração de atingimento das metas de aprendizagem.

É claro que, apesar da (re)organização das atividades e componentes curriculares para o novo cenário, alguns desafios aparecem de imediato como aponta o Parecer CNE/CP no 5/2020, e que devem ser superados pelos diferentes sistemas e redes de ensino (BRASIL, 2020). Podemos citar: como garantir padrões básicos de qualidade para evitar o crescimento da desigualdade educacional no Brasil? Como garantir padrões de qualidade essenciais a todos os estudantes submetidos a regimes especiais de ensino que compreendem atividades não presenciais mediadas ou não por tecnologias digitais de informação?

Sobre esse tema, o documento reafirmou o que está previsto na Medida Provisória n 934/2020 e na Lei de Diretrizes e Bases da Educação Nacional (LDB) 9394/96. Os documentos determinam que os sistemas de ensino possuem autonomia para deliberar sobre flexibilização (BRASIL, 2020). 
Na Educação Superior, dada a maior familiaridade com os meios digitais, assim como a autonomia dos atores envolvidos, foi de certa forma mais fácil adaptar-se à realidade de aulas remotas, ou seja, substituição das disciplinas presenciais por aulas não presenciais. E nesse sentido, é necessário adaptar-se e inovar para garantir aprendizagem e desenvolvimento das competências e habilidades dos alunos e professores.

\section{Percurso metodológico}

O caminho investigativo busca desvelar se detrás de um fenômeno há um problema relevante e de natureza epistemológica. Em segundo lugar tenta (re)organizar os saberes adquiridos ao longo da pesquisa. $O$ presente estudo tem abordagem qualitativa e se desenvolve a partir de um duplo caminho: a revisão bibliográfica e o estudo de caso.

Para Gil (2006), a pesquisa bibliográfica é desenvolvida com base em material já elaborado, ou seja, material oficialmente publicado. E é constituída principalmente de livros e artigo científicos.

A abordagem qualitativa responde às questões particulares. Ela se preocupa, nas ciências sociais, com um nível de realidade que não pode ser quantificada com atitudes, que correspondam a um espaço muito profundo nas relações dos processos e fenômenos (MINAYO et al,. 2007).

E o estudo de caso, para André (2008), focaliza uma situação, um fenômeno em particular. $\mathrm{O}$ caso em si, diz a autora, tem importância seja pelo que revela sobre o fenômeno, seja pelo que representa. É, pois, um tipo de estudo adequado para investigar problemas práticos, questões que emergem do dia a dia.

Desde a introdução deste texto esclarecemos a pretensão de apresentar primeiramente as ações de ensino e aprendizagem nos cursos de Hotelaria e Turismo da UFMA no cenário da COVID19 e, para isso, partimos do levantamento dos assuntos abordados nas lives que aconteceram entre os meses de junho e julho de 2020.

Em um segundo momento foi aplicado um questionário/formulário semiestruturado para os alunos dos cursos, cujo objetivo era capturar as percepções que eles têm sobre as atividades desenvolvidas pelos professores neste período. É importante abordar as percepções dos dicentes, pois para Barbosa (2007) cada um percebe a realidade de forma particular e atribui sentido aos diferentes acontecimentos com base no repertório que possui, elaborado com base nas experiências inerentes ao grupo social ao qual pertence.

Cumpre destacar que para desencadear o processo de produção dos dados da pesquisa, foi feito o contato com os participantes através de e-mail institucional e do aplicativo WhatsApp para onde enviamos o questionário confeccionado no software formato Google forms que auxiliou na análise dos dados que serão apresentadas a seguir.

\section{As revelações da pesquisa}

A pesquisa recebeu 26 respostas de graduandos dos cursos de Turismo e Hotelaria da UFMA, sendo $96,2 \%$ de Hotelaria e 3,8\% de Turismo. Cada entrevista foi codificada com a letra " $E$ " de estudante, seguida de um número para identificar o participante da pesquisa. 
Para a análise dos dados utilizamos o modelo narrativo compreendido como a expressão da experiência humana. E para Costa (1997, p. 8) "narrar é (re) construir de modo escrito ou verbal o presente, as lembranças, os desejos, é (re) elaborar a experiência individual no passado comum".

Após definirmos o corpus, organizamos narrativas dos estudantes em quadros. O cabeçalho desses quadros identifica cada questão da pesquisa.

$\mathrm{Na}$ etapa de tratamento dos resultados, buscamos compreender os significados das narrativas dos estudantes, para isso apontamos o que observamos em cada agrupamento das frases categorizadas. Antes de seguir para a análise dos achados da pesquisa, organizamos de forma resumida quadro com as atividades desenvolvidas pelos docentes de turismo e hotelaria (Quadro 1).

Quadro 1: Minicursos (online) ofertados nos Cursos de Turismo e Hotelaria

\begin{tabular}{|l|}
\hline \multicolumn{1}{|c|}{ Tema } \\
\hline Hospitalidade na Hotelaria Pós-pandemia \\
\hline $\begin{array}{l}\text { Alimento seguro na WEB: tópicos extensivos e atuais sobre segurança e contaminação } \\
\text { alimentar }\end{array}$ \\
\hline Ferramentas de gestão \\
\hline Como realizar pesquisa online \\
\hline Novos protocolos de higiene na hotelaria e restauração \\
\hline
\end{tabular}

Fonte: Elaborado por Correia, 2020.

Os minicursos tiveram em média uma carga horária de 5 (cinco) horas e foram ofertados em um único dia ou turno, e foram realizados através da plataforma digital Google Meet Hangouts. Além desses minicursos, também foram ofertados vários webnários com temas diversos (Quadro 2)

Quadro 2: Webnários ofertados nos cursos de Turismo e Hotelaria

\begin{tabular}{|l|}
\hline \multicolumn{1}{|c|}{ Tema } \\
\hline Experiências internacionais em Turismo e Hospitalidade \\
\hline Transportes turísticos: análise da infraestrutura disponível em São Luís-MA \\
\hline Impactos da pandemia do coronavírus na Hotelaria de São Luís-MA \\
\hline Bem-estar, lazer e ócio em período de pandemia \\
\hline Troca de experiências sobre pesquisa e produção acadêmica em Turismo e Hospitalidade \\
\hline Escolhendo e planejando propostas e projetos de pesquisa em Turismo e Hospitalidade \\
\hline Práticas de Hospitalidade na Fábrica Santa Amélia \\
\hline Estratégias de pequenos negócios maranhenses para enfrentamento da COVID-19 \\
\hline Rio, Sol e Uvas: Enoturismo no Vale do São Francisco \\
\hline $\begin{array}{l}\text { Reflexões sobre Hospitalidade, Turismo e Hotelaria em São Luís: desafios, tendências e } \\
\text { possibilidades }\end{array}$ \\
\hline Turismo e Barreirinhas; olhares transversos \\
\hline Como pesquisar no campo da gastronomia \\
\hline Turismo, Cidades e Patrimônio \\
\hline
\end{tabular}

Fonte: Elaborado por Correia, 2020. 
Assim como os minicursos, os webnários também foram realizados através da plataforma digital Google Meet Hangouts. Em média esses webnários tiveram uma carga horária de três a quatro horas, sendo ofertados em turnos diferentes. $O$ desenvolvimento das atividades no modelo remoto reforça os princípios sóciointercionistas pelo fato de oportunizarem a comunicação e a intervenção do usuário durante o processo e oportuniza a interação dos alunos com os conteúdos e com os colegas e professores (BARROS; CARVALHO, 2019).

O primeiro questionamento feito aos alunos foi saber se as atividades online (webnários) nos cursos de Turismo e Hotelaria contribuem para a aprendizagem. Nesse questionamento conseguimos 24 respostas e apresentamos as mais relevantes (Quadro 3):

Quadro 3: Contribuições das aulas para o aprendizado do aluno de Hotelaria e Turismo

\section{Contribuições}

Contribuem positivamente, pois ajuda a "manter", de certa forma, o cérebro em movimento com atividades relacionadas à nossa área de atuação profissional (E1).

Contribuem para manter o nosso senso crítico; aumentar o nosso conhecimento nos mantendo atualizados com os acontecimentos específicos da nossa área em relação à pandemia da COVID-19. Sendo, a melhor opção para o momento atual (E3).

Sendo uma forma alternativa para obter certa qualificação neste momento em que as aulas presenciais estão suspensas (E5).

É uma oportunidade para não parar o aprendizado (E10).

São de grande importância, pois há uma troca de experiências, de falas entre mestres/doutores/especialistas da área com alunos contribuindo de forma mútua gerando esse conhecimento aplicado nas nossas vidas diante desse cenário pandêmico (E21).

Diante do cenário atual, onde não há aula e por diversas vezes o aluno não se vê obrigado a estudar, essas "lives" contribuem para que meus conhecimentos dentro do meu curso não fiquem parados mesmo com a falta de aula presencial (E25).

Fonte: Elaborado por Correia, 2020

O principal elemento em destaque é o conhecimento, ou seja, que estas atividades possibilitam a produção e (re)organização de saberes. Sobre esse ponto, Primo (2000, p. 60) diz que "as novas tecnologias da informação e da comunicação vêm contribuindo para a modificação da forma de as pessoas se relacionarem e de construírem conhecimentos". É importante destacar que a elaboração de novos saberes nos ambientes digitais é compartilhada, isso sugere que a aprendizagem é alguma coisa que se faz em grupos, como explicam Barros e Carvalho (2019).

Em seguida pedimos aos alunos que destacassem os pontos positivos e negativos do modelo de ensino remoto nos cursos de Turismo e Hotelaria da UFMA (Quadro 4). 
Quadro 4: Pontos Positivos do modelo de ensino remoto

\section{Pontos Positivos}

Continuidade dos estudos, mesmo em quarentena; cuidar da saúde mental combatendo o ócio na pandemia; participar de atividades em grupo mesmo que a distância (E26).

Poder contar com bons profissionais para dar continuidade nos ensinamentos (E21).

Conhecimentos que são adquiridos e repassados entre professor e alunos virtualmente que muitas das vezes o professor não consegue passar tudo em uma sala de aula. E a questão do distanciamento social nessa pandemia (E18).

Ajuda o aluno a ter conhecimentos além dos que são abordados em sala. Gera o anseio do aluno a buscar mais e pesquisar mais, sendo assim não ficar acomodado com a situação atual do mundo.

A fácil propagação de várias temáticas de forma simples e inclusiva (E13).

Fonte: Elaborado por Correia, 2020

Aprender com o uso de tecnologias no leva a pensar e aplicar novos parâmetros de disseminação e compartilhamento do conhecimento. Sobre isso, Moran (2018) explica que:

\footnotetext{
Hoje as tecnologias digitais móveis, conectadas, leves ubíquas são o motor e a expressão do dinamismo transformador, da aprendizagem por compartilhamento [...]. Hoje, não são só apoio do ensino, são eixos estruturantes de uma aprendizagem criativa, critica, empreendedora, personalizada e compartilhada (PÉREZ GÓMEZ, 2015 apud MORAN, 2018, p. 10).
}

No Quadro 4, os entrevistados destacam mais uma vez esse aprendizado compartilhado com os professores e seus pares, a continuidade dos estudos, as oportunidades de explorar novos saberes, e esse deve ser o papel da universidade no processo de ensino e aprendizagem: incentivar a reflexão e a elaboração do conhecimento e o uso de novas técnicas. O professor, por sua vez, como o mediador deve criar caminhos que contribuam para o desenvolvimento de habilidades técnicas e socioemocionais, atitudes e competências de forma significativa e alinhada ao contexto da instituição de ensino e do aluno.

Entendemos ainda, a partir das narrativas dos estudantes, que além da importância da troca de experiências, o ensino remoto possibilita o acesso a diferentes referências teóricas. Portanto, o espaço digital utilizado para as atividades remotas é um lugar de criação, inovação, reflexão e compartilhamento, também inclusivo, considerando os princípios de equidade e qualidade. 
Quadro 5: Pontos negativos destacados pelos alunos

\section{Pontos Negativos}

Custo alto na aquisição de pacotes de dados e internet banda larga; falta de treinamento que nos possibilitasse usar as ferramentas utilizadas nas aulas (Zoom e Google Meet); falta de divulgação dos horários e links para acessar as aulas.

Falta treinamento aos docentes para uso adequado das ferramentas online.

Conexão com internet, investimento em tecnologias para se incluir nas atividades.

É a distância mesmo, em termos de adaptação neste novo ramo.

pouco convívio com os colegas; falta de acessibilidade para alunos que não tem recursos necessários para participar das lives, inclusive.

muitos não conseguem ter de assistir às lives devido à falta de acesso à Internet e equipamentos de informática para que possam participar.

Possibilidade de dispersão, pois as aulas são na internet; custo alto com pacotes de dados e de banda larga para assistir às aulas; necessidade de possuir equipamentos caros, como notebooks ou smartphones.

Pouca interação entre os participantes que às vezes ficam mais tímidos do que normalmente seriam presencialmente, pessoas que não têm internet não podem participar, as aulas se tornam mais cansativas e as vezes monótonas.

Alguns alunos não possuem equipamentos necessários para assistir ou interagir nas atividades remotas.

Fonte: Elaborado por Correia, 2020.

Os alunos destacaram principalmente a dificuldade de acesso a pacotes de internet e equipamentos adequados para assistir às atividades ofertadas nos cursos, e outro aspecto é o despreparo de professores no uso das tecnologias.

O primeiro dado que precisamos lembrar é que nem todo mundo tem equipamentos que possibilitam o acesso à internet. O IBGE, na Pesquisa Nacional por Amostra de Domicílios (PNAD), aponta, em 2017, que 74,9\% das residências brasileiras utilizavam internet. Esse número chega a $80,1 \%$ em residências urbanas e $41 \%$ em residências rurais. Cabe ressaltar que a pesquisa do IBGE também buscou levantar os motivos pelos quais $25,1 \%$ dos domicílios brasileiros não têm (ou não tinham naquele momento) acesso à internet: "[...] as respostas variam entre: falta de interesse no serviço, valor do serviço de acesso, ninguém da residência sabe usar internet e o equipamento para acessar é muito caro, conforme gráfico abaixo [...]" (IBGE, 2017).

Os dispositivos mais disponíveis para os brasileiros são, portanto, os telefones celulares. Em 2019, tínhamos 420 milhões de dispositivos digitais (computadores e smartphones) circulando no Brasil, o que soma 2 (dois) dispositivos por habitante. A distribuição desses dispositivos, no entanto, nem sempre é igualitária.

De acordo com dados da PNAD do último trimestre de 2018, o percentual de jovens estudantes com 14 anos ou mais que possuem acesso à internet ultrapassa $95 \%$ nas três primeiras regiões, $81 \%$ na região Norte e $86 \%$ na região Nordeste. Quando se incluem os jovens entre 10 e 13 anos, os percentuais mantêm-se na faixa de 92\% nas regiões Sul, Sudeste e Centro-Oeste e cai para 71\% na região Norte e 79\% na região Nordeste (ARRUDA, 2020). 
Portanto, se considerarmos apenas o ensino superior, na melhor das hipóteses, teríamos menos de $2 \%$ dos estudantes sem acesso a equipamentos e internet ao considerarmos os dados do IBGE/PNAD 2018, ou 10\% das famílias sem acesso à internet e mais de $13 \%$ sem acesso a computadores (não se considerando a posse de celulares), a partir dos dados da ANDIFES (2018), referentes aos alunos de Instituições Federais de Ensino Superior.

Nesse sentido, utilizando-se os dados que apresentam os menores percentuais de acesso à internet, teríamos a presença de cerca de 120 mil alunos sem acesso à internet e que exigiram, portanto, políticas específicas de acesso a equipamento e dados.

Sobre esse aspecto, Arruda (2020) explica que se considera ainda que os maiores níveis de pobreza da população encontram-se nas regiões Norte e Nordeste. Os dados mostram, dessa forma, relativo destaque das regiões Sul, Sudeste e Centro-Oeste no que diz respeito aos números de acesso à internet e equipamentos.

A Universidade Federal do Maranhão, devido à pandemia da Covid-19, por meio da Pró-Reitoria de Assistência Estudantil (PROAES), divulgou edital PROAES 29/2020 referente ao Auxílio Inclusão Digital em duas modalidades: pacote de dados e empréstimo de tablets. As inscrições foram abertas até o mês de agosto de 2020. Nesse sentido, a UFMA busca auxiliar o estudante em condição de vulnerabilidade socioeconômica para realização das atividades remotas do calendário acadêmico.

O Auxílio Inclusão Digital, na modalidade pacote de dados para acesso à internet, consiste na cessão de dados móveis do Serviço Móvel Pessoal (SMP); o Auxílio Inclusão Digital - Modalidade Pacote de Dados, para acesso à internet, em caráter emergencial, em razão da pandemia causada pelo COVID-19 e da necessidade de desenvolver as atividades acadêmicas remotas; e, ainda, o Auxílio Inclusão Digital Modalidade Plena (Empréstimo de Tablet), em caráter emergencial, para os discentes regulamente matriculados na UFMA, em razão da pandemia causada pela COVID-19 e necessidade de desenvolver as atividades acadêmicas remotas.

A falta da mão de obra qualificada técnica computacional e, sobretudo, professores preparados pedagogicamente também para o uso da tecnologia na educação é um segundo aspecto que precisa de atenção nas universidades públicas. Nesse caso, Barros e Carvalho apontam que

a maioria dos professores não faz parte dessa geração, e, por isso, têm resistência para compreender essas inovações. Mas, é o professor que deve exercer a função de orientar os alunos quanto ao uso e caminhos a serem trilhados com as novas tecnologias (BARROS; CARVALHO, 2019, p. 214).

A partir do ineditismo deste novo cenário, na educação, os professores enfrentam novos desafios e procuram se adaptar. Um dos maiores desafios, para muitos docentes, é a dificuldade em aprender a utilizar novas ferramentas, planejamento das aulas em outro formato, entre outros que estão exigindo deles formação contínua para o "novo normal" nas escolas. É necessário aos professores perceberem que o mundo 
evoluiu e que o jeito de fazer educação hoje não é o mesmo de outrora. Tempos atrás, o professor era o único participante ativo em sala de aula, somente ele tinha o conhecimento e transmitia para seus alunos, sem muita participação ou grandes reflexões sobre o conteúdo. Hoje, o professor continua sendo o mentor em sala de aula, mas, além disso, ele agora é mediador e orientador dos caminhos percorridos pelos alunos, tem o papel de buscar novas alternativas para desenvolver a aprendizagem dos alunos.

Na Universidade Federal do Maranhão, por exemplo, tendo em vista o cenário da pandemia da Covid-19, a Diretoria Interdisciplinar de Tecnologias na Educação (Dinte) se mobilizou para criar alternativas de qualificação de professores. Dentre as ações foram ofertados webnários com temáticas da EaD de grande interesse ao professor da UFMA que precisa adquirir conhecimentos para iniciar as suas ações docentes, incorporando as tecnologias na educação.

\section{Considerações finais}

A educação é um direito de todos e este deve obedecer aos princípios da equidade e qualidade. Nesse tempo desafiador, a educação precisa se adequar ao "novo normal", ou seja, criar situações, espaços e metodologias capazes de despertar a curiosidade do alunado e permitir pensar o concreto, conscientizar-se da realidade, questioná-la e construir conhecimentos para transformá-la, superando a ideia de que ensinar é sinônimo de transferir conhecimento.

No contexto da Universidade Federal do Maranhão, foram tomadas várias iniciativas desde a paralisação em março de 2020, para diminuir a distância entre os professores e alunos, e para continuar os estudos teóricos e práticos. Primeiramente, a Dinte criou o Portal EaD para Você, a fim de auxiliar técnicos e professores na produção de conteúdo voltado para o ambiente virtual, por meio de cursos, treinamentos e webnários. Em seguida, com a publicação da Resolução no 1.999/2020-Consepe, estabeleceu-se o Calendário Acadêmico Especial da Graduação. E mais recente, o retorno das atividades acadêmicas que serão de forma remota e/ou híbrida, cujo sistema de ensino adotado, temporariamente, visa desenvolver os componentes curriculares possibilitando a interação discente-docente-conhecimento.

O ensino remoto é, prioritariamente, mediado por tecnologias na educação, já o híbrido, realizado de forma planejada, são ações presenciais e remotas, que reduzem a convivência dos envolvidos no mesmo espaço físico, com a finalidade de viabilizar o processo ensino-aprendizagem.

Nos cursos de Hotelaria e Turismo da UFMA, em reunião dos seus respectivos colegiados, ficou definido que a oferta de competentes curriculares e o planejamento acadêmico estarão de acordo com processo de Ensino Emergencial Remoto, ou seja, serão aulas totalmente virtuais, com o uso da internet, e considerando as especificidades de cada curso.

A fim de minimizar as desigualdades e desafios durantes as aulas remotas, a Universidade tem buscado alternativas para auxiliar os estudantes, uma delas foi o lançamento de dois editais para inclusão digital dos alunos em vulnerabilidade socioeconômica, incluindo o acesso à internet, com a utilização de chips e entrega de ta- 
blets. E para os professores, tem ofertado treinamentos sobre o uso de tecnologias a fim de que possam realizar suas atividades remotas com melhor integração à dinâmica educacional da atualidade e apresentar novas alternativas de ensino e aprendizagem.

\section{Referências}

ANDRÉ, Marli. Eliza Dalmazo Afonso de. Estudo de caso em pesquisa educacional. 3. ed. Brasília: Liber Livro Editora, 2008. (Série Pesquisa, v. 13).

ANDIFES - Associação Nacional dos Dirigentes das Instituições Federais de Ensino Superior. V pesquisa Nacional de Perfil Socioeconômico e cultural dos (as) Graduandos (as) das IFES -2018. Disponível em: https://www.andifes.org.br/wp-content/uploads/2019/05/V-Pesquisa-Nacional-de-Perfil-Socioeconomico-e-Cultural-dos-as-Graduandos-as-das-IFES-2018.pdf. Acesso em: 11 ago. 2020.

ARRUDA, Eucidio Pimenta. Educação Remota Emergencial: elementos para políticas públicas na educação brasileira em tempos de COVID-19. EmRede Revista de Educação a Distância, v. 7, n. 1, p. 257-275, 2020.

BARBOSA, Maria Carmen Silveira. Culturas escolares, culturas de infância e culturas familiares: as socializações e a escolarização no entretecer destas culturas. Educação e Sociedade, Campinas, v. 28, n. 100, p. 1059-1083, out. 2007.

BARROS, Maria das Graças; CARVALHO, Ana Beatriz Gomes. As concepções de interatividade nos ambientes virtuais de aprendizagem. In: SOUSA, Robson Pequeno; MOITA, Filomena da M. C. da S. C.; CARVALHO, Ana Beatriz G. (orgs.). Tecnologias digitais na educação. Campina Grande: EDUEPB, 2019.

BRASIL, Decreto MEC no 9.057, de 25 de maio de 2017. Disponível em: http://www. planalto.gov.br/. Acesso em: 10 jul. 2020.

BRASIL. IBGE. PNAD - Acesso à Internet e à televisão e posse de telefone móvel celular para uso pessoal 2017. Brasília: IBGE, 2018.

COSTA. Cléria Botêlho da. Uma história sonhada. Revista Brasileira de História, São Paulo, v. 17, n. 34, p. 52-65, 1997.

GIL, Antonio Carlos. Como elaborar projetos de pesquisa. 4 ed. São Paulo: Atlas, 2006.

HODGES, Charles et al. The difference between emergency remote teaching and online learning. EDUCAUSE Review, 27 mar. 2020. Disponível em: https://er.educause. edu/articles/2020/3/the-difference-between-emergency-remote-teaching-and-online-learning, 2020. Acesso em: 11 ago. 2020.

MAIA, Carmem; MATAR, João. ABC da EAD: a educação a distância hoje. Pearson Prentice Hall, 2018. 
MEC. Ministério da Educação. Portaria $\mathbf{n}$ o 343. Dispõe sobre a substituição das aulas presenciais por aulas em meios digitais enquanto durar a situação de pandemia do Novo Coronavírus - COVID-19. Disponível em: https://www.semesp.org.br/legislacao/ portaria-no-343-de-17-de-marco-de-2020. Acesso em: 15 ago. de 2020.

MEC. Ministério da Educação. Decreto no 9057/2017. Dispõe sobre a oferta de cursos na modalidade a distância. Disponível em: https://www.semesp.org.br/legislacao/decreto-mec-n-9-057-de-25-de-maio-de-2017. Acesso em: 15 ago. de 2020.

MEC. Ministério da Educação. Medida Provisória $\mathbf{n}^{\circ} \mathbf{9 3 4 / 2 0 2 0}$. Estabelece normas excepcionais sobre o ano letivo da educação básica e do ensino superior. Disponível em: https://www.congressonacional.leg.br/materias/medidas-provisorias. Acesso em: 20 ago. 2020.

MEC. Ministério da Educação.. Lei de Diretrizes e Bases da Educação Nacional (LDB) 9394/96. Brasília-DF, 1996.

MEC. Ministério da Educação.. Parecer CNE/CP no 5/2020. Reorganização do Calendário Escolar em razão da Pandemia da COVID-19. Disponível em: http://portal.mec.gov. $\mathrm{br} /$ conselho-nacional-de-educacao/atos-normativos--sumulas-pareceres-e-resolucoes. Acesso em: 10 set. 2020.

MINAYO, Maria Cecília De Souza et al. Pesquisa social: Teoria, método e criatividade. Petrópolis-RJ: Editora Vozes, 2007.

MORAN, José. Metodologias ativas para uma aprendizagem mais profunda. In: $\mathrm{BACl}-$ $\mathrm{CH}$, Lilian; MORAN, José (orgs.). Metodologias ativas para uma educação inovadora: uma abordagem prática. Porto Alegre: Penso, 2018.

MORIN, Edgar; DÍAZ, Carlos Jesús Delgado. Reinventar a Educação: abrir caminhos para a metamorfose da humanidade. São Paulo: Palas Athena, 2016.

PRIMO, Alex Fernando Teixeira. Ferramentas de interação na web: travestindo o ensino tradicional ou potencializando a educação através da cooperação? Disponível:http:// books.scielo.org/. Acesso em: 18 set. 2020.

SARAIVA, Karla; VEIGA-NETO, Alfredo. Modernidade líquida, capitalismo cognitivo e educação contemporânea. Educação \& Realidade, Porto Alegre, v. 34, n. 2, p. 187201, maio/ago. 2009.

UFMA - Universidade Federal do Maranhão. Resolução № 1.999-CONSEPE. Dispõe sobre o Calendário Acadêmico Especial da Graduação em virtude da situação decorrente do novo Coronavírus (SARS-COV-2 /COVID-19). Disponível em: http://www.ufma.br/ portalUFMA/arquivo/xzpukG9ox7HIfgv.pdf. Acesso em: 11 ago. de 2020. 


\section{Informações complementares}

Financiamento

Não se aplica

Contribuição de autoria

Concepção e elaboração do manuscrito: Jonilson Costa Correia.

Coleta de dados: Jonilson Costa Correia

Análise de dados: Jonilson Costa Correia.

Discussão dos resultados: Jonilson Costa Correia.

Revisão e aprovação: Jonilson Costa Correia.

Preprint, originalidade e ineditismo

O artigo é original, inédito e não foi depositado como preprint.

Consentimento de uso de imagem

Não se aplica.

Aprovação de Comitê de Ética em Pesquisa

Não se aplica.

Conflito de interesse

Não há conflitos de interesse.

Conjunto de dados de pesquisa

Não há dados disponibilizados.

Licença de uso

Os autores cedem à Revista Pesquisa e Debate em Educação os direitos exclusivos de primeira publicação, com o trabalho simultaneamente licenciado sob a Licença Creative Commons Attribution (CC BY) 4.0 International. Esta licença permite que terceiros remixem, adaptem e criem a partir do trabalho publicado, atribuindo o devido crédito de autoria e publicação inicial neste periódico. Os autores têm autorização para assumir contratos adicionais separadamente, para distribuição não exclusiva da versão do trabaIho publicada neste periódico (ex.: publicar em repositório institucional, em site pessoal, publicar uma tradução, ou como capítulo de livro), com reconhecimento de autoria e publicação inicial neste periódico.

\section{Publisher}

Universidade Federal de Juiz de Fora (UFJF), Faculdade de Educação (FACED), Centro de Políticas Públicas e Avaliação da Educação (CAEd), Programa de Pós-Graduação Profissional em Gestão e Avaliação da Educação Pública (PPGP). Publicação no Portal de Periódicos da UFJF. As ideias expressadas neste artigo são de responsabilidade de seus autores, não representando, necessariamente, a opinião dos editores ou da universidade.

\section{Editores}

Frederico Braida; Liamara Scortegagna; Wagner Silveira Rezende. 
Formato de avaliação por pares

Revisão duplamente cega (Double blind peer review).

Sobre os autores

\section{Jonilson Costa Correia}

Graduado em Hotelaria (UFMA). Especialista em Metodologia do Ensino Superior (UFMA). Mestre em Educação (UFMA). Doutor em Educação (UFMG). Professor Classe do Departamento de Turismo e Hotelaria da Universidade Federal do Maranhão. Líder do Núcleo de Projetos e Pesquisas em Hotelaria (UFMA)

Currículo Lattes: http://lattes.cnpq.br/7829720263155717 